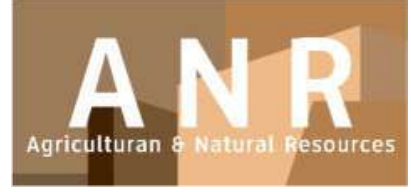

PAPER - OPEN ACCESS

\title{
Pemanfaatan Data Sifat Tanah Dalam Pendugaan Laju Infiltrasi Pada Areal Hutan Berlereng Curam
}

\author{
Author : Bejo Slamet, dkk \\ DOI $\quad: 10.32734 /$ anr.v2i1.575 \\ Electronic ISSN : :2654-7023 \\ Print ISSN : :2654-7015
}

Volume 2 Issue 1-2019 TALENTA Conference Series: Agricultural and Natural Resources (ANR)

\section{(2) $(1) \Theta$}

This work is licensed under a Creative Commons Attribution-NoDerivatives 4.0 International License.

Published under licence by TALENTA Publisher, Universitas Sumatera Utara

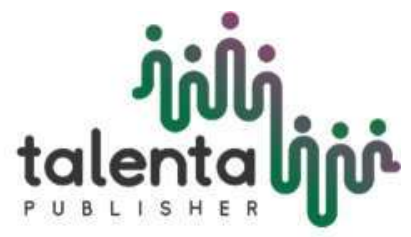




\title{
jiali in \\ ANR Conference Series 02 (2019) \\ TALENTA Conference Series
}

tolontiabioi

Available online at https://talentaconfseries.usu.ac.id

\section{Pemanfaatan Data Sifat Tanah Dalam Pendugaan Laju Infiltrasi Pada Areal Hutan Berlereng Curam}

\author{
(The Utilization of Soil Properties Data in Estimating Infiltration Rate in Forest Areas with steep slopes)
}

\author{
Bejo Slamet $^{\mathrm{a} *}$, Dewi Sagita Ginting ${ }^{\mathrm{b}}$ dan Deni Elfiati ${ }^{\mathrm{c}}$ \\ ${ }^{a}$ Departemen Manajemen Hutan, Fakultas Kehutanan, Universitas Sumatera Utara, Medan \\ ${ }^{b}$ Alumnus Fakultas Pertanian Universitas Sumatera Utara, Medan \\ ${ }^{c}$ Departemen Budidaya Hutan, Fakultas Kehutanan, Universitas Sumatera Utara, Medan
}

Email: bejo@usu.ac.id

\begin{abstract}
Abstrak
Kendala pengukuran infiltrasi pada lahan hutan pegunungan adalah posisi lokasi yang jauh dan mempunyai kelerengan yang curam sampai sangat curam. Penelitian ini dilakukan untuk mendapatkan model hubungan antara sifat tanah pada areal hutan yang berlereng curam dengan laju infiltrasi. Penelitian dilakukan di Taman Hutan Raya (Tahura) Bukit Barisan Kabupaten Karo Provinsi Sumatera Utara. Sifat tanah yang dijadikan sebagai parameter penduga adalah tekstur tanah, bulk density (kepadatan tanah) dan bahan organik. Pengukuran infiltrasi di lapangan dilakukan dengan metode double ring infiltrometer. Hasil penelitian menunjukkan bahwa fraksi liat, bulk density, porositas dan bahan organic mampu memberikan nilai pendugaan laju infiltrasi maksimum dengan koefisien determinasi (R2) sebesar 0,567 dan pendugaan waktu mencapai konstan dengan koefisien determinasi (R2) sebesar 0,760. Adapaun model persamaan penduga laju infiltrasi minimum hanya memberikan nilai koefisien determinasi sebesar 0,162 . Variabilitas spasial laju infiltrasi yang tinggi mengakibatkan pendugaan menggunakan sifat fisik tanah masih memberikan koefisisen determinasi yang rendah. Namun demikian model persamaan ini dapat dijadikan sebagai penduga infiltrasi pada areal pebukitan dengan kelerengan curam dan jauh dari sumber air.
\end{abstract}

Kata Kunci : infiltrasi, sifat tanah, hutan pegunungan, areal berlereng curam

\begin{abstract}
The constraints on measuring infiltration on mountain forest land are the remote locations and have steep slopes to very steep. This research was conducted to obtain a model of the relationship between the soil properties in steep slope forests with infiltration rates. The study was held in the Bukit Barisan Forest Park (Tahura), Karo Regency, North Sumatra Province. The properties of the soil which are used as estimating parameters are soil texture, bulk density and soil organic matter. Measurement of infiltration in the field was done by $t$ double ring infiltrometer method. The results show that the clay fraction, bulk density, porosity and soil organic matter were able to provide the estimation values of maximum infiltration rate with a coefficient of determination ( 2 2) of 0.567 and the estimation of constant time with a coefficient of determination (R2) of 0.760. However, the estimation equation of minimum infiltration rate model only gives a determination coefficient of 0.162 . The high spatial variability of infiltration rate in the field resulting in the low of the coefficient of determination of the model. However, this equation model can be used as an estimator of infiltration in hills with steep slopes and far from water sources.
\end{abstract}

Keywords: infiltration, soil properties, mountain forests, steep slope areas

(C) 2019 The Authors. Published by TALENTA Publisher Universitas Sumatera Utara

Selection and peer-review under responsibility of Pertemuan Ilmiah Tahunan (PIT) dan Seminar Nasional Ke-4,

Komunitas Manajemen Hutan Indonesia (KOMHINDO)

p-ISSN: 2654-7015, e-ISSN: 2654-7023, DOI: 10.32734/anr.v2i1.575 


\section{Pendahuluan}

Ekosistem hutan pegunungan mempunyai peran penting dalam memelihara keseimbangan ekosistem daerah bawahannya melalui fungsi hidroorologi hutan. Proses distribusi air hujan menjadi aliran permukaan oleh tegakan hutan erat kaitannya dengan pencegahan erosi dan banjir. Salah satu fungsi utama hutan yang berubah akibat dikonversi menjadi tutupan atau penggunaan lain adalah fungsi hidrologisnya. Hutan mempunyai fungsi hidrologi yang penting, utamanya dalam mendistribusikan besaran curah hujan yang jatuh diatasnya hingga ke permukaan tanah [1]. Curah hujan yang sampai di tajuk pohon ditahan tajuk tersebut, dan diantaranya menjadi tetesan air hujan secara langsung menerobos celah-celah antara daun-daun dan ranting-ranting, dan akhirnya sampai ke permukaan tanah sebagai throughfall dan sebagian mengalir melalui batang sebagai stemflow, sisanya yang tidak sampai di permukaan tanah disebut dengan intersepsi [2]. Air hujan yang sampai di permukaan tanah melalui throughfall dan stemflow sebagian diinfiltrasikan ke dalam tanah [3] dan sebagian menjadi aliran permukaan [4]. Salah satu hal penting dalam distribusi air hujan adalah infiltrasi.

Kawasan hutan pegunungan sebagian besar berada pada wilayah dengan kelerengan curam sampai sangat curam. Kawasan berlereng merupakan suatu kawasan yang sangat jarang dilakukan pengukuran infiltrasi. Hal ini terjadi karena pada kawasan ini sulit dilakukan pengukuran infiltrasi yang disebabkan sulitnya menempatkan alat dan sulit mendapatkan air. Untuk mempermudah pendugaan besarnya laju infiltrasi dikawasan berlereng maka perlu dilakukan penelitian tentang pendugaan laju infiltrasi dengan memanfaatkan sifat-sifat tanah. Sifat-sifat hidraulik tanah menentukan infiltrasi, aliran permukaan, dan transport nutrisi di dalam tanah [5, 6], dalam beberapa kasus aliran air juga berkaitan erat dengan mekanisme transfer agen kimiawi di dalam tanah yang berpengaruh terhadap kualitas air [7]. Data karakteristik sifat tanah diperlukan untuk menjelaskan respon hidrologi terhadap suatu kejadian hujan [8]. Tujuan penelitian ini adalah membuat model hubungan antara beberapa sifat tanah dengan laju infiltrasi pada areal hutan yang berlereng terjal $(25-40 \%)$.

\section{Metode Penelitian}

Penelitian lapangan dilaksanakan di Tahura Bukit Barisan Desa Tongkoh, Kecamatan Dolat Rakyat, Kab. Karo Provinsi Sumatera Utara. Analisis tanah dilakukan di Laboratorium Central Fakultas Pertanian Universitas Sumatera Utara. Alat yang digunakan adalah double ring infiltrometer, stopwatch, pita ukur, penggaris, ember atau jerigen, suunto clinometer, ring sample, plastik, tally sheet, alat tulis, kertas label, kalkulator.

Penentuan titik pengambilan data infiltrasi dengan cara purposive sampling pada kawasan berlereng antar $25-40 \%$ dengan sepuluh kali ulangan pengukuran infiltrasi. Pengukuran infiltrasi dilakukan dengan double ring infiltrometer (Gambar 1). Contoh tanah tidak terganggu (undisturb soil samplle) diambil dengan menggunakan ring sampel tanah untuk pengukuran bulk density tanah (Gambar 1). Sampel tanah terganggu diambil secara komposit dari sekitar lokasi titik pengukuran infiltrasi. Sampel tanah terganggu digunakan untuk analisis tekstur tanah dan bahan organik tanah. Penetapan tekstur tanah dilakukan dengan metode hydrometer.

Pendugaan persamaan laju infiltrasi dengan memanfaatkan data tekstur tanah, kerapatan tanah (bulk density), porositas dan bahan organik tanah diformulasikan dalam persamaan regresi berganda sebagai berikut:

$\mathrm{Y}=\mathrm{f}(\mathrm{X} 1, \mathrm{X} 2, \mathrm{X} 3, \mathrm{X} 4)$

Dimana:

$\mathrm{Y}=$ Laju infiltrasi; $\mathrm{X} 1$ = fraksi Liat; $\mathrm{X} 2$ = bulk density; $\mathrm{X} 3=$ porositas; $\mathrm{X} 4$ = bahan organik 


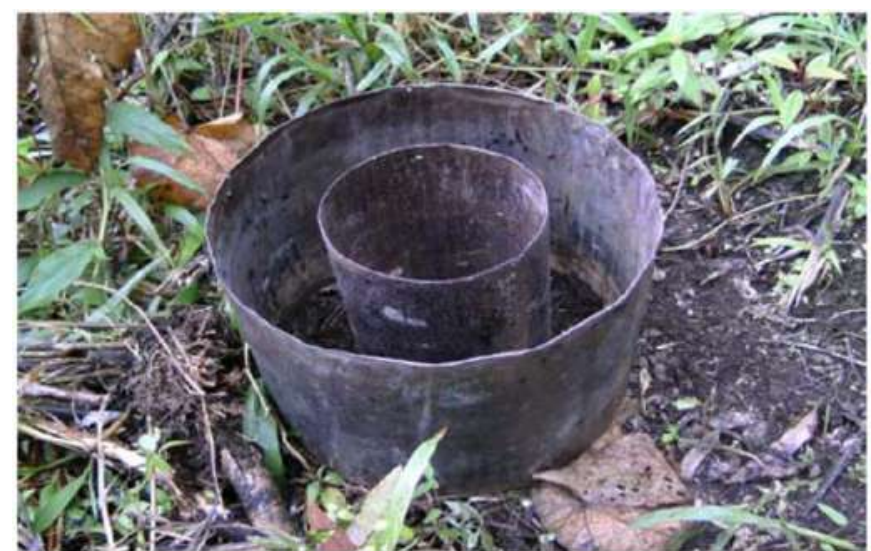

(a) Alat double ring infiltrometer

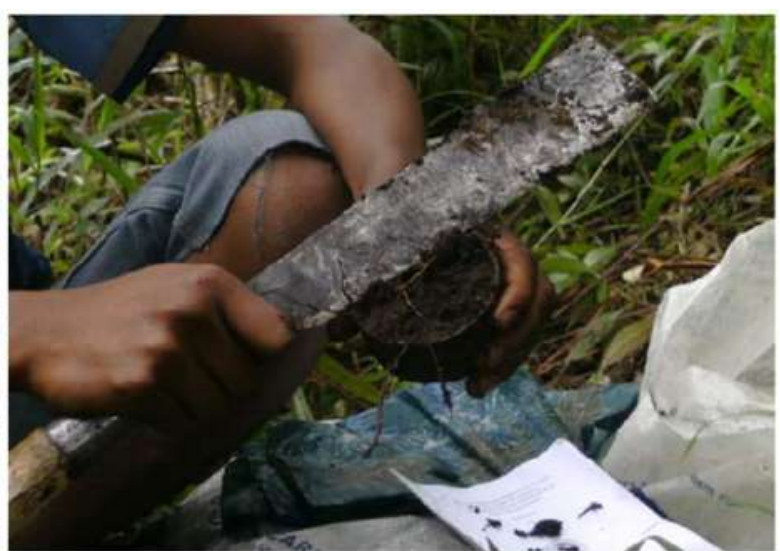

(b) Pengambilan contoh tanah tidak terganggu

Gambar 1. Alat double ring infiltrometer dan pengambilan contoh tanah tidak terganggu

\section{Hasil Dan Pembahasan}

\subsection{Laju infiltrasi}

Hasil pengukuran infiltrasi pada areal hutan dengan kelerengan 25-40\% sangat bervariasi yang ditunjukkan oleh nilai koefisien variasi lebih besar dari 30\%, yaitu mencapai 59,38\% (Tabel 1). Hasil pengukuran kapasitas infiltrasi pada kawasan berlereng terjadi variasi kapasitas infiltrasinya yaitu 1,2 cm/jam, $12 \mathrm{~cm} / \mathrm{jam}, 2,4 \mathrm{~cm} / \mathrm{jam}, 1,2 \mathrm{~cm} / \mathrm{jam}, 6$ $\mathrm{cm} / \mathrm{jam}, 4,8 \mathrm{~cm} / \mathrm{jam}, 4,8 \mathrm{~cm} / \mathrm{jam}, 3,6 \mathrm{~cm} / \mathrm{jam}, 2,4 \mathrm{~cm} / \mathrm{jam}, 0,6 \mathrm{~cm} / \mathrm{jam}$ dengan waktu mencapai konstan secara berurutan adalah 100 menit, 110 menit, 20 menit, 25 menit, 30 menit, 30 menit, 30 menit, 70 menit, 30 menit, dan 70 menit.

Tabel 1. Hasil pengukuran infiltrasi

\begin{tabular}{cc}
\hline Ulangan & Laju infiltrasi (cm/Jam) \\
\hline 1 & 47,85 \\
2 & 24,28 \\
3 & 14,86 \\
4 & 6,36 \\
5 & 14,16 \\
6 & 8,32 \\
7 & 26,25 \\
8 & 25,12 \\
9 & 13,77 \\
10 & 35,02 \\
\hline Rataan & 21,60 \\
Simpangan Baku & 12,83 \\
Koefisien variasi (\%) & 59,38 \\
\hline
\end{tabular}

Infiltrasi merupakan proses yang komplek bergantung pada sifat-sifat tanah dan sifat hujan serta kondisi awal dan batas dalam domain aliran [9]. Variabilitas spasialnnya tinggi meskipun dengan jarak yang dekat karena yang mempengaruhi infiltrasi bukan hanya faktor tanahnya. Laju infiltrasi di kebun sawit di laporkan hanya setengah dari laju infiltrasi hutan alam [10]. Hasil penelitian Banabas, et al. [11] di Papua Nugini terjadi variabilitas spasial yang signifikan antara laju infiltrasi di jalur panen, piringan batang sawit dan gawangan mati tempat penumpikan pelepah 
sawit. Laju infiltrasi meningkat secara berturut-turut jalur panen < piringan batang sawit < gawangan mati. Laju infiltrasi yang rendah pada piringan batang sawit dan jalur panen terjadi karena pemadatan tanah dan rendahnya tumbuhan bawah akibat bekas pijakan kaki saat aktifitas pemanenan tandan buah maupun bekas roda alat angkut.

Kapasitas infiltrasi dibawah tegakan hutan secara umum tinggi dan sangat tinggi karena efek kombinasi antara suplai kontinyu dari serasah daun, aktifitas fauna tanah dan pembusukan akar. Sebagai hasilnya potensi terjadinya infiltration-excess overland flow (HOF) adalah rendah yaitu aliran yang terjadi jika besarnya hujan (intensitas hujan) yang jatuh lebih besar dari kapasitas infiltrasi [12].

Aktifitas pengelolaan lahan yang mengakibatkan pemadatan tanah dapat merubah kapasitas infiltrasi dan menghilangkan fungsi hidrologi permukaan untuk meningkatkan infiltrasi. Rab [13] mengemukakan bahwa aktifitas yang menyebabkan pemadatan tanah dilaporkan secara nyata telah meningkatkan bobot isi (BI) tanah dan menurunkan total porositas dan makroporositas tanahnya. Suryatmojo [14] mengemukakan bahwa pada tapak-tapak yang terganggu sehingga terjadi pemadatan tanah menyebabkan peluang terjadinya aliran permukaan yang dimulai pada tapak-tapak yang terganggu tersebut. Kapasitas infiltrasi tanah mengendalikan suplai air ke dalam cadangan air tanah, yang kemudian mempengaruhi kondisi aliran dasar. Peningkatan kapasitas infiltrasi berdampak pada lebih tingginya jumlah aliran dasar [15].

\subsection{Sifat Sifat Tanah}

Sifat tanah untuk masing-masing areal yang diukur infiltrasinya secara lengkap disajikan pada Tabel 2. Sifat fisik tanah dilokasi penelitian relatif tidak berbeda untuk bulk density dan porositas yang ditunjukkan oleh nilai standar deviasi dan nilai variasi koefisien yang kecil. Bahan organik tanah mempunyai variabilitas yang cukup tinggi yaitu sebesar 23,43\%. Persentase debu merupakan sifat fisik tanah dengan variabilitas yang paling tinggi yang ditunjukkan oleh nilai koefisien variasi mencapai 41,87\%. Kandungan bahana organic tanah di lokasi penelitian termasuk dalam kategori sangat tinggi karena rataannya mencapai lebih dari 5\%. Bahan organik termasuk kompos dilaporkan sangat efektif dalam meningkatkan infiltrasi [16], sehingga keberadaan bahan organic tanah di lokasi penelitian penting untuk meningkatkan laju infiltrasi.

Tabel 2. Hasil pengukuran sifat-sifat tanah untuk masing-masing ulangan pengukuran

\begin{tabular}{lcccccccc}
\hline Ulangan & $\begin{array}{c}\text { Bulk } \\
\text { density } \\
(\mathrm{gr} / \mathrm{cm} 3)\end{array}$ & $\begin{array}{c}\text { Porosita } \\
\text { s } \\
(\%)\end{array}$ & $\begin{array}{c}\text { C- } \\
\text { Organik }\end{array}$ & $\begin{array}{c}\text { Bahan } \\
\text { organik } \\
(\%)\end{array}$ & $\begin{array}{c}\% \\
\text { Pasir }\end{array}$ & $\begin{array}{c}\% \\
\text { Debu }\end{array}$ & $\begin{array}{c}\% \\
\text { Liat }\end{array}$ & Tekstur \\
\hline 1 & 0,831 & 68,83 & 13,28 & 22,84 & 86,56 & 5,00 & 8,44 & Pasir berlempung \\
2 & 0,837 & 68,41 & 11,04 & 18,99 & 85,56 & 6,00 & 8,44 & Pasir berlempung \\
3 & 0,859 & 67,6 & 8,79 & 15,12 & 86,56 & 6,00 & 7,44 & Pasir berlempung \\
4 & 0,906 & 65,81 & 11,21 & 19,28 & 76,56 & 11,00 & 12,44 & $\begin{array}{l}\text { Lempung } \\
\text { berpasir }\end{array}$ \\
5 & 0,877 & 66,9 & 10,71 & 18,42 & 85,56 & 6,00 & 8,44 & Pasir berlempung \\
6 & 0,835 & 68,49 & 6,55 & 11,27 & 83,56 & 9,00 & 7,44 & Pasir berlempung \\
7 & 0,896 & 66,21 & 12,77 & 21,96 & 76,56 & 14,00 & 9,44 & Lempung \\
& & & & & & & & \\
8 & 0,937 & 64,64 & 9,83 & 16,91 & 75,56 & 15,00 & 9,44 & Lempung \\
9 & 1,007 & 62,01 & 7,76 & 13,35 & 86,56 & 6,00 & 7,44 & Pasir berlempung \\
10 & 0,835 & 68,49 & 6,55 & 11,27 & 85,56 & 7,00 & 7,44 & Pasir berlempung \\
\hline $\begin{array}{l}\text { Rataan } \\
\text { Simpangan }\end{array}$ & 0,887 & 66,544 & 10,217 & 17,571 & 82,56 & 8,67 & 8,77 & \\
baku & 0,06 & 2,16 & 2,39 & 4,11 & 4,67 & 3,63 & 1,55 & \\
CV (\%) & 6,40 & 3,25 & 23,43 & 23,42 & 5,65 & 41,87 & 17,66 & \\
\hline
\end{tabular}




\subsection{Hubungan infiltrasi dan sifat-sifat tanah}

Hasil uji multikolinearitas maka diperoleh hasil yang menyatakan terjadinya kolinearitas antara ketiga komponen yaitu fraksi pasir, debu, dan liat. Sebagai peubah pewakil diambil fraksi liat karena dari ketiga komponen tersebut, fraksi liat merupakan komponen yang mempunyai tingkat pengaruh yang paling tinggi terhadap model. Selain uji multikolinearitas, juga dilakukan uji heteroskedastisitas yang menunjukkan bahwa pada tingkat kepercayaan $90 \%$ peubah bebas yang digunakan merupakan peubah yang mempengaruhi atau layak digunakan dalam pembuatan model, sehingga peubah bebas yang paling baik untuk menduga laju infiltrasi maksimum, minimum dan waktu untuk mencapai konstan adalah fraksi liat, bulk density, porositas, dan bahan organik.

Hasil analisis regresi diperoleh hasil persamaan hubungan antara laju infiltrasi maksimum, laju infiltrasi minimum, dan waktu mencapai konstan sebagai berikut:

$$
\begin{aligned}
& \text { Laju infiltrasi maksimum }=-162,574-2,583 \text { X1 }+44,039 \text { X2 }+92,404 \text { X3 }+0,482 X 4 \quad(\mathrm{R} 2=0,567) \\
& \text { Laju infiltrasi Minimum }=352,933-1,131 \text { X1 }-102,748 \text { X2 }-197,174 \text { X3 }+2,106 \text { X4 }(\mathrm{R} 2=0,162) \\
& \text { Waktu mencapai konstan }=98385,652-20,215 \text { X } 1-29171,7 \text { X2-55002,6 X3 } 337,202 \text { X4 } \quad(R 2=0,760)
\end{aligned}
$$

Keterangan :

$$
\begin{array}{ll}
\mathrm{X} 1 & \text { : Fraksi Liat }(\%) \\
\mathrm{X} 2 & \text { : Bulk density }(\mathrm{gr} / \mathrm{cm} 3) \\
\mathrm{X} 3 & \text { : Porositas }(\%) \\
\mathrm{X} 4 & \text { : Bahan Organik }(\%)
\end{array}
$$

Hasil analisis regresi menunjukkan bahwa faktor yang mempengaruhi besarnya laju infiltrasi adalah fraksi liat, bahan organik, bulk density, dan porositas tanah, dengan nilai koefisien determinasi masing-masing model penduga mulai dari kapasitas infiltrasi maksimum, minimum dan waktu untuk mencapai konstan secara berturut turut adalah $0,567,0,162$ dan 0,760. Nilai koefisien determinasi sebesar 0,567 pada persamaan penduga Laju infiltrasi maksimum berarti $56 \%$ variabel Laju infiltrasi maksimum dipengaruhi oleh fraksi liat, bulk density, porositas, dan bahan organik tanah, sisanya $44 \%$ dipengaruhi oleh faktor lain selain parameter yang digunakan dalam persamaan atau model. Demikian halnya untuk persamaan penduga laju infiltrasi minimum yang hanya sebesar 0,162 berarti $16 \%$ variabel Yminimum dipengaruhi oleh fraksi liat, bulk density, porositas dan bahan organik tanah, sisanya $84 \%$ dipengaruhi oleh faktor lainnya. Persamaan penduga waktu konstan mempunyai nilai koefisien determinasi sebesar 0,760 berarti $76 \%$ variabel waktu mencapai konstan dipengaruhi oleh fraksi liat, bulk density, porositas, dan bahan organik tanah, sisanya 34\% dipengaruhi oleh faktor lain selain parameter yang digunakan dalam persamaan atau model. Persamaan penduga laju infiltrasi minimum karena mempunyai koefisien determinasi yang rendah tidak layak untuk direkomendasikan untuk menduga laju infilrasi minimum. Sedangkan untuk persamaan laju infiltrasi maksimum dan waktu mencapai konstan masih memungkinkan untuk dipergunakan karena mempunyai nilai koefisien determinasi yang cukup baik. Mengingat sulitnya pengukuran infiltrasi di daerah berlereng terjal maka persamaan ini cukup membantu manakali pendugaan infiltrasi terkendala karena berbagai faktor.

\section{Kesimpulan}

Sifat tanah yang mampu memberikan nilai pendugaan cukup baik terhadap laju infiltrasi maksimum adalah fraksi liat, bulk density, porositas dan bahan organic dengan koefisien determinasi (R2) sebesar 0,567 dan pendugaan waktu mencapai konstan dengan koefisien determinasi (R2) sebesar 0,760. Besarnya koefisien determinasi model persamaan penduga laju infiltrasi minimum hanya memberikan sebesar 0,162. Variabilitas spasial laju infiltrasi yang tinggi mengakibatkan pendugaan menggunakan sifat fisik tanah masih memberikan koefisisen determinasi yang rendah. Namun demikian model persamaan ini dapat dijadikan sebagai penduga infiltrasi pada areal pebukitan dengan kelerengan curam dan jauh dari sumber air. 


\section{Referensi}

[1] L. A. Bruijnzeel, "Hydrological functions of tropical forests: not seeing the soil for the trees?," Agriculture, Ecosystems and Environment, vol. 104, pp. 185-228, 2004.

[2] Q. Xiao and E. G. McPherson, "Rainfall interception by Santa Monica’s municipal urban forest," Urban Ecosystems, vol. 6, pp. 291-302, 2002.

[3] J. L. Robinson, L. D. Slater, and K. V. R. Schäfer, "Evidence for spatial variability in hydraulic redistribution within an oak-pine forest from resistivity imaging," Journal of Hydrology vol. 430-431, pp. 69-79, 2012.

[4] A. Trabucco, R. J. Zomer, D. A. Bossio, O. v. Straaten, and L. V. Verchot, "Climate change mitigation through afforestation/reforestation: A global analysis of hydrologic impacts with four case studies," Agriculture, Ecosystems and Environment, vol. 126, pp. 81-97, 2008.

[5] H. Bormann and K. Klaassen, "Seasonal and land use dependent variability of soil hydraulic and soil hydrological properties of two Northern German soils," Geoderma, vol. 145, pp. 295-302, 2008.

[6] W. Hu, M. Shao, Q. Wang, J. Fan, and R. Horton, "Temporal changes of soil hydraulic properties under different land uses," Geoderma, vol. 149, pp. 355-366, 2009.

[7] C. Morris and S. J. Mooney, "A high-resolution system for the quantification of preferential flow in undisturbed soil using observations of tracers," Geoderma, vol. 118, pp. 133-143, 2004.

[8] L. Descroix, J. L. G. Barrios, J. P. Vandervaere, D. Viramontes, and A. Bollery, "An experimental analysis of hydrodynamic behaviour on soils and hillslopes in a subtropical mountainous environment (Western Sierra Madre, Mexico)," Journal of Hydrology, vol. 266, pp. 1-14, 2002.

[9] S. Assouline, "Infiltration into soils: Conceptual approaches and solutions," Water Resources Research, vol. 49, pp. 1755-1772, 2013.

[10] Sunarti, N. Sinukaban, B. Sanim, and S. D. Tarigan, "Konversi hutan menjadi lahan usaha tani karet dan kelapa sawit serta pengaruhnya terhadap aliran permukaan dan erosi tanah di DAS Batang Pelepat," Jurnal Tanah Tropika, vol. 13, pp. 253-260, 2008.

[11] M. Banabas, M. A. Turner, D. R. Scotter, and P. N. Nelson, "Losses of nitrogen fertiliser under oil palm in Papua New Guinea: 1. Water balance, and nitrogen in soil solution and runoff," Australian Journal of Soil Research, vol. 46, pp. 332-229, 2008.

[12] H. Grip, J. Fritsch, and L. Bruijnzeel, "Soil and water impacts during forest conversion and stabilisation to new land use," in Forests,water and people in the humid tropics. Past, present and future hydrological research for integrated land and water management, M. Bonell and L. A. Bruijnzeel, Eds., ed Cambridge: Cambridge University Press, 2005, pp. 561-589.

[13] M. A. Rab, "Changes in physical properties of a soil associated with logging of Eucalyptus regnan forest in southeastern Australia," Forest Ecology and Management, vol. 70, pp. 215-229, 12// 1994.

[14] H. Suryatmojo, "Recovery of Forest Soil Disturbance in the Intensive Forest Management System," Procedia Environmental Sciences, vol. 20, pp. 832-840, 2014.

[15] S. Soedarjanto, J. Sartohadi, M. P. Hadi, and P. Danoedoro, "The role of vegetation cover and catchment characteristics on baseflow in Bali island," Indonesian Journal of Geography, vol. 43, pp. 97-110, 2011.

[16] N. C. Olson, J. S. Gulliver, J. L. Nieber, and M. Kayhanian, "Remediation to improve infiltration into compact soils," J Environ Manage, vol. 117, pp. 85-95, Mar 152013. 